Article

\title{
Optimization of Classification Prediction Performances of an Instrumental Odour Monitoring System by Using Temperature Correction Approach
}

\author{
Giuseppina Oliva ${ }^{1}\left(\mathbb{D}\right.$, Tiziano Zarra ${ }^{1, *} \oplus$, Raffaele Massimo ${ }^{1}$, Vincenzo Senatore ${ }^{1}\left(\right.$, Antonio Buonerba ${ }^{2} \oplus$, \\ Vincenzo Belgiorno ${ }^{1}$ and Vincenzo Naddeo ${ }^{1}$ (I) \\ 1 Department of Civil Engineering, Sanitary Environmental Engineering Division (SEED), \\ University of Salerno, Via Giovanni Paolo II 132, 84084 Fisciano, SA, Italy; goliva@unisa.it (G.O.); \\ raf.massimo@gmail.com (R.M.); vsenatore@unisa.it (V.S.); v.belgiorno@unisa.it (V.B.); vnaddeo@unisa.it (V.N.) \\ 2 Inter-University Centre for Prediction and Prevention of Relevant Hazards (Centro Universitario per La \\ Previsione e Prevenzione Grandi Rischi, C.U.G.RI.), Fisciano Campus, University of Salerno, \\ Via Giovanni Paolo II 132, 84084 Fisciano, SA, Italy; abuonerba@unisa.it \\ * Correspondence: tzarra@unisa.it; Tel.: +39-089-969335
}

\section{check for}

updates

Citation: Oliva, G.; Zarra, T.; Massimo, R.; Senatore, V.; Buonerba,

A.; Belgiorno, V.; Naddeo, V.

Optimization of Classification

Prediction Performances of an Instrumental Odour Monitoring System by Using Temperature Correction Approach. Chemosensors 2021, 9, 147. https://doi.org/ $10.3390 /$ chemosensors 9060147

Academic Editor: Pierluigi Barbieri

Received: 14 May 2021

Accepted: 14 June 2021

Published: 16 June 2021

Publisher's Note: MDPI stays neutral with regard to jurisdictional claims in published maps and institutional affiliations.

Copyright: (c) 2021 by the authors. Licensee MDPI, Basel, Switzerland. This article is an open access article distributed under the terms and conditions of the Creative Commons Attribution (CC BY) license (https:// creativecommons.org/licenses/by/ $4.0 /)$.

\begin{abstract}
Odour emissions generated by industrial and environmental protection plants are often a cause of nuisances and consequent conflicts in exposed populations. Their control is a key action to avoid complaints. Among the odour measurement techniques, the sensory-instrumental method with the application of Instrumental Odour Monitoring Systems (IOMSs) currently represents an effective solution to allow a continuous classification and quantification of odours in real time, combining the advantages of conventional analytical and sensorial techniques. However, some aspects still need to be improved. The study presents and discusses the investigation and optimization of the operational phases of an advanced IOMS, applied for monitoring of environmental odours, with the aim of increasing their performances and reliability of the measures. Accuracy rates of over $98 \%$ were reached in terms of classification performances. The implementation of automatic correction systems for the resistance values of the measurement sensors, by considering the influence of the temperature, has been proven to be a solution to further improve the reliability of IOMS. The proposed approach was based on the application of corrective coefficients experimentally determined by analyzing the correlation between resistance values and operating conditions. The paper provides useful information for the implementation of real-time management activities by using a tailor-made software, able to increase and enlarge the IOMS fields of application.
\end{abstract}

Keywords: air quality; continuous monitoring; linear discriminant analysis; MOS sensor; odour emissions

\section{Introduction}

The operation of industrial plants and of waste and wastewater treatment plants may entail the alteration of some environmental components, such as the air quality sector, with introduction into atmosphere of gaseous pollutants, including odours [1]. Odours emissions can cause annoyance to the exposed population and therefore complaints due to perception of unhealthy conditions and low quality of air [2,3]. Prolonged exposure to odorous gaseous mixtures can be responsible for several symptoms such as nausea, headache, and respiratory problems [4-6]. Even if the exposure to odour emissions was not related to permanent health effects, a comprehensive assessment and control of these emissions to increase the plants acceptability is needed [7].

The control of odour emissions is thus a key action that plant managers can implement to boost the social and environmental sustainability of odour-emitting plants.

To date, it has not been adopted worldwide a shared regulations framework for odour characterization and measurement [8]. However, the numerous research activities in this 
field suggest to assess odours with integrated strategies, starting from the characterization of the odours emissions at the receptors level [9].

Currently, measurement and quantification of odour can be implemented with instrumental, sensorial and mixed methods [10]. The instrumental techniques allow to identify and quantify the chemical composition of the odours gaseous mixtures, using separation and analytical identification techniques such as gas chromatography combined with mass spectrometry $[11,12]$. These techniques have the advantage of being consolidated and objective, as well as being repeatable and accurate. However, they are not able to reflect the odour offensiveness of gaseous mixture. Sensory techniques, such as dynamic olfactometry, use the human nose as detector in the evaluation of odours. Due to the subjective nature of the perception of odour sensation and the influence of external factors on measurements, dynamic olfactometry is generally related to uncertainty, even if conducted according to the EN 13725:2003 [13]. On the other hand, among the senso-instrumental techniques, the Instrumental Odour Monitoring Systems (IOMSs), also known as electronic noses, are able to monitor odours continuously, combining the advantages of both conventional instrumental and sensorial measurement techniques. Therefore, a high potential of future development has been associated to IOMS-based technologies [14,15]. In 2018, the German VDI (Association of German Engineers) published a guideline (VDI 3518-3:2018) relating specifically to odour measurements with IOMSs. In Italy, as consequence of a significantly growth of the use of IOMSs during the last years, in February 2019, the UNI Standardization Body elaborated and approved a specific standard (UNI 1605848:2019) for the application and qualification of IOMS for environmental odour monitoring in ambient air. Furthermore, during the last years several national and international standards and regulations in terms of odours have been introduced, confirming importance and actuality of the topic $[9,16]$.

IOMSs are capable of monitoring odours using a specific array of measurement sensors and a set of algorithms for the elaboration of the acquired data $[17,18]$. Since the idea of an electronic nose was born in 1982, both the sensor array and the algorithms have been affected by constant significant developments associated with the continuous improvement of machine learning technologies $[17,19]$. The electronic nose has found wide application in different sectors such as agriculture [20,21], medical diagnosis [22,23], environmental monitoring [24,25], and food safety protection [26,27]. For a specific application, the design of the hardware components of the device and the selection of the most suitable sensors, as well as the methods of feature extraction and classification, are fundamental elements to optimize. The IOMS can be implemented to obtain real-time information needed to support the decision making processes, with a proactive approach and to control the performance of the processes (Figure 1) [28,29]. However, even if it is difficult to implement at an industrial scale, synergistic approaches based on chemical characterization, dynamic olfactometry, and electronic noses have been demonstrated to have the best performances to characterize odors, evaluate their concentration and to develop innovative and tailored monitoring systems [30]. With these approaches, it is indeed possible to integrate and validate the monitoring results obtained with IOMS with a comprehensive point of view [31,32].

The operating phases of an IOMS are generally: training, validation, measurement and management $[27,33,34]$. Despite the many advantages associated with IOMSs, they still have limitations, such as the difficulty in stabilizing the operating temperature of the devices, the marked dependence of the sensor resistances on operating parameters (temperature, flow rate entering the measurement chamber, humidity, etc.), and possible difficulties in the classification procedure following an improper choice of the method of feature extraction [35]. The challenge of research is therefore to find answers to these critical issues.

The study is aimed at the development of an advanced IOMS applied for environmental odour monitoring in ambient air, with the objective of overcoming some of the above-mentioned limitations. The experimental analyses have been carried out by considering the operational phases of the IOMS. Optimization of the classification performance 
has been reported and highlighted by introducing innovative management systems to stabilize the temperature inside the chamber. Moreover, it has been proposed a smart approach able to automatically process the raw data acquired by the sensors to consider temperature fluctuations, which may occur for unfavourable operating conditions. The temperature inside the chamber significantly affects the values detected by the sensors [36]. It has been extensively demonstrated that under constant gas composition and concentration, the sensor responses change with the variations of temperature and humidity and consequently different methods have been proposed [37,38]. The novel proposed approach was designed by experimentally retrieving the correlation curves between temperatures and resistances for the calculation of specific corrective factors. The results demonstrated a significant improvement in terms of recognition performances by applying the proposed approach for the classification of real odour sampling.

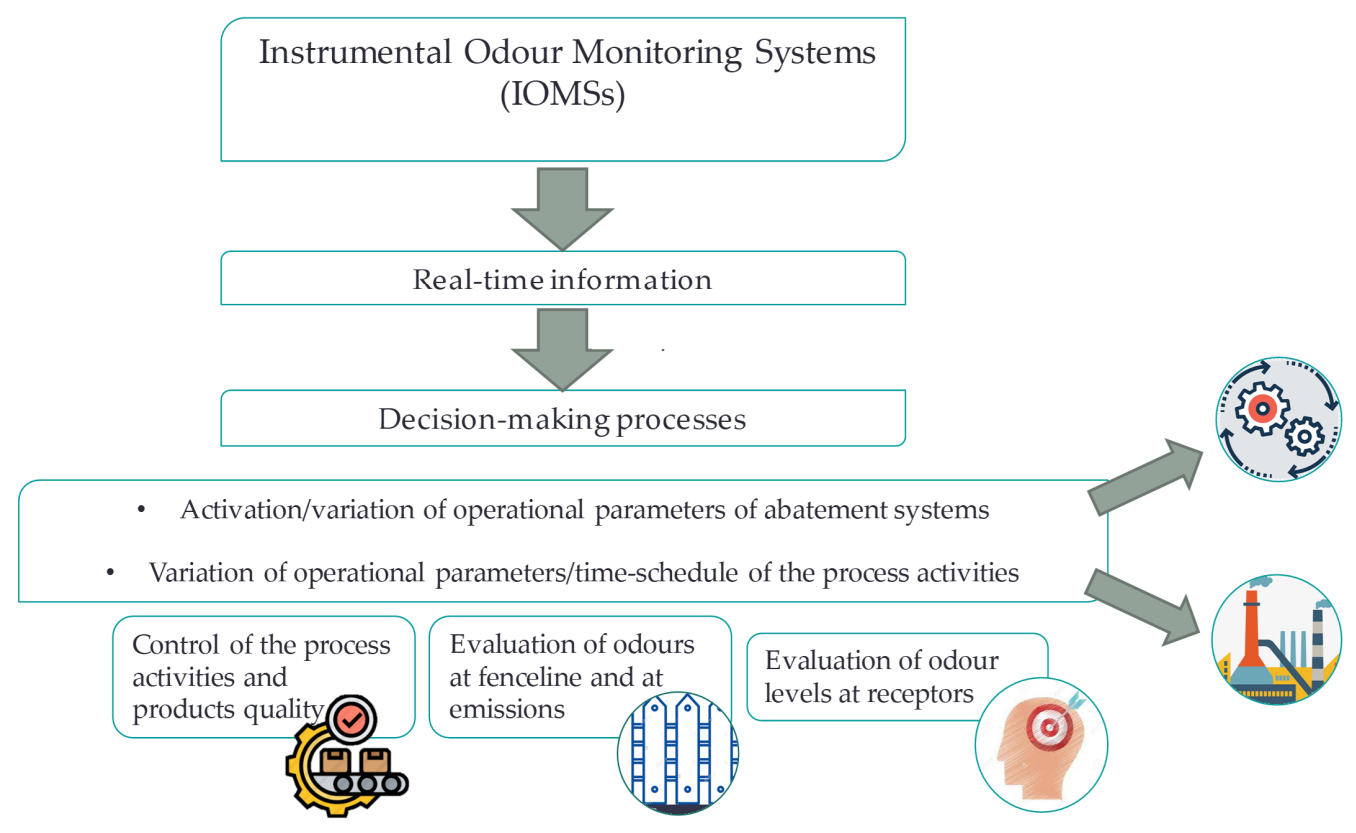

Figure 1. IOMS device-application fields.

\section{Materials and Methods}

\subsection{IOMS Device}

The IOMS device was developed by the research group of the Sanitary Environmental Engineering Division (SEED) of the University of Salerno in collaboration with the SPONGE (www.spongeitalia.com; accessed on 15 June 2021) and SARTEC (www.sartec.it; accessed on 15 June 2021) companies. The developed IOMS is equipped with integrated management, cleaning and calibration systems which allows its automatic use and application even in particularly aggressive environments for prolonged periods. The hardware component of the IOMS system consists of four main units: sampling, measurement, elaboration and management (Figure 2). The sampling component consists of membrane pumps and electronic valves designed to convey the sampled gas at a constant flowrate of $300 \mathrm{~mL}$ $\mathrm{min}^{-1}$ in the measuring chamber. The measuring chamber, called CODE, designed and patented by the SEED research group, is equipped with 16 measurement sensors arranged on two levels (Table 1) and has an internal volume of $300 \mathrm{~mL}$ with a residence time of $1 \mathrm{~min}$. The management unit is composed of systems capable of generating zero air and span air. The elaboration unit, composed by a CPU Board and a Main Board, allows the storage, process, and display of the data acquired by the sensors. The IOMS is equipped with a specific software able to work with five different operating modalities (Baseline, Calibration, Training, Validation, Real Time) [1]. 


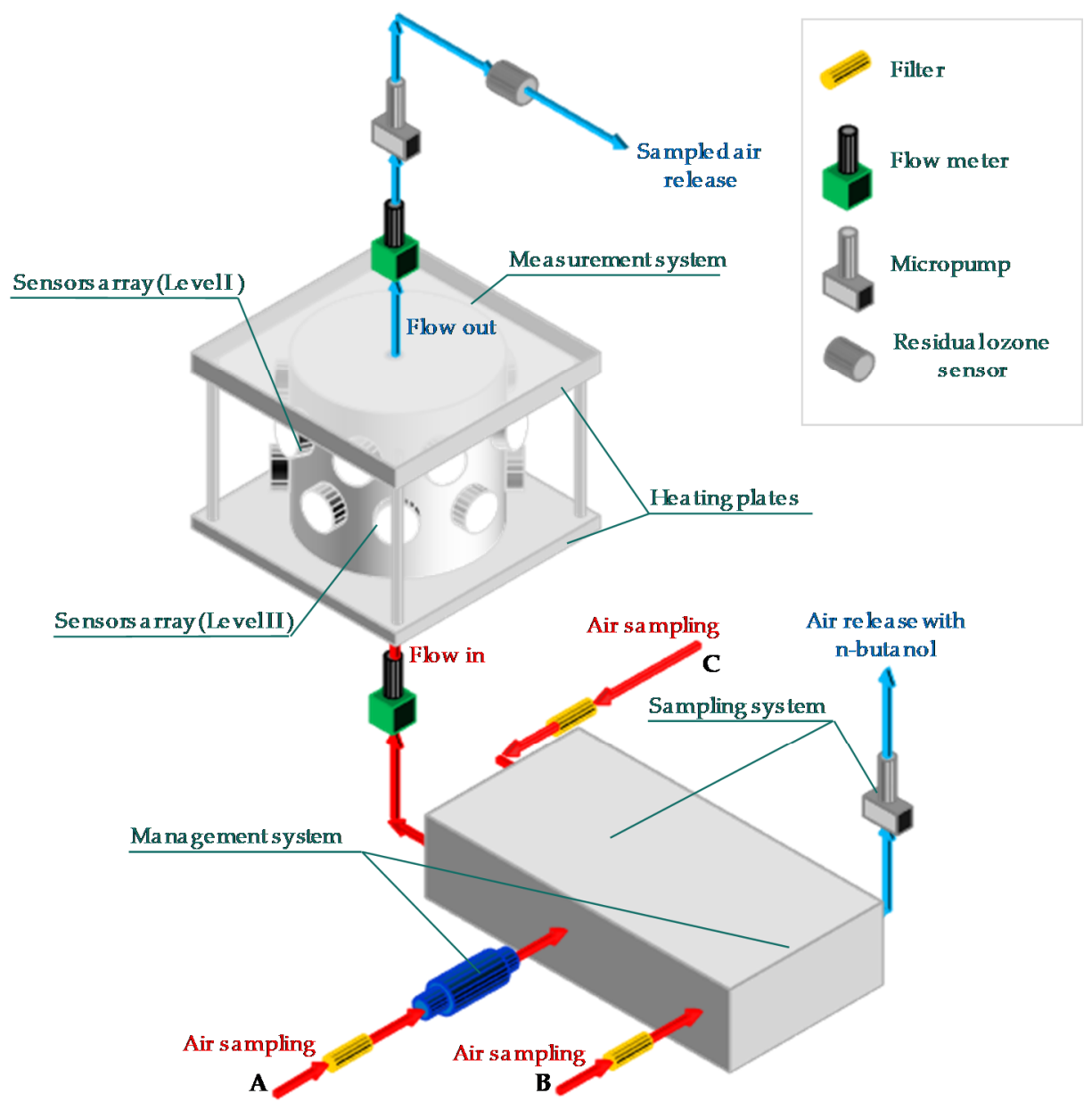

Figure 2. IOMS layout.

Table 1. IOMS sensors and related channels.

\begin{tabular}{cc}
\hline Type of Sensor & Position \\
\hline TGS813 (Combustible Gases) & (Level I, channel j3-Level II, channel j12) \\
TGS2620 (Solvent Vapors) & (Level I, channel j2-Level II, channel j10) \\
TGS2602 (VOCs and odorous gases) & (Level I, channel j15-Level II, channel j9) \\
TGS822 (Organic Solvent Vapors) & (Level I, channel j13-Level II, channel j7) \\
TGS880 (alcohol, odor) & (Level I, channel j8-Level II, channel j1) \\
TGS2600 (hydrogen and carbon monoxide) & (Level I, channel j6-Level II, channel j14) \\
TGS2603 (Odor and Air Contaminants) & (Level II, channel j5) \\
TGS2611 (Methane) & (Level II, channel j4) \\
PID sensor (miniPID 2, Ion Science) & (Level I) \\
Humidity-Temperature Module (HYT271, IST) & (Level I) \\
\hline
\end{tabular}

\subsection{Experimental Analyses}

Four real odour classes were trained for the experimental analysis, sampled at a refining plant ("RF"), from the organic fraction of municipal solid waste ("OF"), coffee aroma ("CA"), and ambient air ("AA"), by using the static lung-effect sampler and $7 \mathrm{~L}$ Nalophan bags. The lung-effect sampler (length $730 \mathrm{~mm}$, diameter $160 \mathrm{~mm}$ ) used has a volume of $10 \mathrm{~L}$, a filling time of 30 to $60 \mathrm{~s}$ and a maximum vacuum output of $500 \mathrm{mbar}$. The systems allowed to collect odour samples in gas sampling bags besides hindering the odour samples contamination. A total of 146 samples were taken.

Table 2 shows the numerical distribution of the total collected samples in the different odor classes. 
Table 2. Training samples dataset.

\begin{tabular}{cccccc}
\hline Odour Classes & RP & OF & CA & AA \\
\hline $\begin{array}{c}\text { Number of samples } \\
\text { Total }\end{array}$ & 24 & 38 & & 40 & 44 \\
\hline
\end{tabular}

The samples were then connected to the IOMS for the acquisition. 138 samples were used to create the Training Set (TS), while the remaining 8 ( 2 for each class) were used as Validation Set (VS). The preliminary validation was performed on TS and on the whole set of samples (TS + VS).

\subsection{Elaboration of the Classification Predicitve Model}

The Linear Discriminant Analysis (LDA) was used for the creation of the predictive classification model. The LDA approach belongs to the supervised methods [39,40]. The elaboration of the prediction models has been implemented with a specific function of the software developed for the IOMS applications [41].

The sensor array generated a vector of resistance every $T_{A}$ seconds for $T_{F}$ minutes and so it gave as output $n$ vectors of $m$ components, where:

- $\mathrm{m}$ is the number of the sensors;

- $\mathrm{T}_{\mathrm{A}}$ (Acquisition time) is the time between two different acquisition of resistance equal to $2 \mathrm{~s}$;

- $\quad \mathrm{a}$ is the number of acquisition;

- $\mathrm{T}_{\mathrm{F}}$ (Flushing duration) is the acquisition time between which the values of resistances were taken in consideration for the calculation of the average value equal to $3 \mathrm{~min}$.

For each sample, the software automatically created a Response Matrix "R" (axm) with the data recorded by the MOS sensors. These matrixes have been preprocessed with the following equation according to a previous study [1].

- $\quad$ Differential Value of resistance (DVR)

$$
f_{i, j}=r_{i, j}-r_{i, 0}
$$

For each pre-processed matrix, a vector per sample was extracted by calculating the average of the values per columns. In this way, for each sample of the Training Set, a vector was automatically generated by the SW. The Feature Extraction (FE) matrix contained a vector for each sample of a Training Set (TS).

The matrixes with the preprocessed data (one vector for each sample of the TS) and the vector with the corresponding odour classes (one value for each sample) were analysed with the LDA method according to [42]. The LDA statistical procedure was implemented returning in output the vectors of the coefficients of the predictive classification model, the confusion matrix, and the Mahalanobis distances.

\subsection{Analysis of the Influence of the Temperature on the Sensors Detected Values}

The influence of the variation of the detected temperature inside the CODE chamber and the resistance values of the 14 measurement sensors has been evaluated statistically during the acquisition phase. For the TS + VS datasets, for each odour class, correlation graphs were elaborated, implementing linear interpolation analyses. For each sensor, the R-squared coefficient of the correlation curves Temperature-Resistance was calculated according to [43]. The corrective coefficients were calculated for the sensors, which showed a R-squared coefficient higher than 0.7 .

\subsection{Optimization Studies and Performance Evaluation}

In order to improve the accuracy of the classification predictive models, the set of corrective coefficients obtained by analyzing the temperature influence was applied to the raw resistance data of the measurement sensors. These coefficients were used only for 
sensors in which the relationship between $\mathrm{T}$ and $\mathrm{R}$ showed a correlation coefficient higher than 0.7 .

To calculate the corrective coefficients, it has been implemented the following algorithm:

(a) Calculation of the interpolation curves equations $R i, j=a j T i, j+b j$ (where $R i, j$ are the resistance values, $T i, j$ the corresponding temperature and $a j$ and $b j$ are the linear combination coefficients different for each $j$-esimo sensor);

(b) Calculation of the benchmark values at $50{ }^{\circ} \mathrm{C}$, for each sensor, using the corresponding equation of the interpolation curves (R50: reference value at temperature of $50^{\circ} \mathrm{C}$ );

(c) Calculation of the reference values for each value of temperature between $40^{\circ} \mathrm{C}$ and $60{ }^{\circ} \mathrm{C}$ and for each sensor, using the corresponding equation of the interpolation curves (RTk: reference value at temperature $T k\left(40-60{ }^{\circ} \mathrm{C}\right)$ );

(d) Calculation of the corrective coefficients as the ratio between the RTk and R50, different for each $j$-esimo sensor and for $k$-esimo Temperature.

The obtained corrective coefficients have been automatically applied at each values of resistance according to the mean value of the temperature measured inside the chamber in the acquisition time.

To quantify the effectiveness of the proposed approach, the performance of the classification prediction model was calculated and evaluated by defining the indicators listed below [44].

- Average System Accuracy corresponds to the average per class effectiveness in the recognition of samples by the classifier.

$$
\frac{\sum_{i=1}^{l} \frac{t p_{i}+t n_{i}}{t p_{i}+f n_{i}+f p_{i}+t n_{i}}}{l} .
$$

- System Error is the average error per class in the recognition of samples made by classifier.

$$
\frac{\sum_{i=1}^{l} \frac{f p_{i}+f n_{i}}{t p_{i}+f n_{i}+f p_{i}+t n_{i}}}{l} .
$$

- Precision $(\mu)$ represents the concordance of the labels of the data classes with those attributed by the classifier if calculated from the sums of the decisions per text.

$$
\frac{\sum_{i=1}^{l} t p_{i}}{\sum_{i=1}^{l}\left(t p_{i}+f p_{i}\right)}
$$

- Recall $(\mu)$ indicates the effectiveness of a classifier in identifying class labels if calculated through the sum of the decisions per text.

$$
\frac{\sum_{i=1}^{l} t p_{i}}{\sum_{i=1}^{l}\left(t p_{i}+f n_{i}\right)}
$$

- $\quad F$-score $(\mu)$ identifies the relationships between positive data labels and those provided by a classifier based on the sum of decisions by text.

$$
\frac{\left(\beta^{2}+1\right) \text { Precision }_{\mu} \text { Recall }_{\mu}}{\beta^{2} \text { Precision }_{\mu}+\text { Recall }_{\mu}} .
$$

where:

- $\quad l=$ number of the classes;

- $\quad t p_{i}=$ true positive, represents the number of gaseous samples of the $i$-class correctly recognized in the $i$-class;

- $\quad t n_{i}=$ true negative, represents the number of samples of a different class correctly recognized out of the $i$-class; 
- $\quad f p_{i}=$ false positive, represents the number of samples of a different incorrectly attributed to the $i$-class;

- $\quad f n_{i}=$ false negative, represents the number of samples of the $i$-class attributed to a different class.

For an individual class $C i$, the assessment is defined by singular accuracy, precision, and recall. Conversely, the quality of the overall classification has been assessed as the sum of counts to obtain cumulative $t p, f n, t n, f p$ (micro-averaging).

\section{Results and Discussion}

\subsection{Predicitve Model for Odour Classification}

Table 3 reports the confusion matrix obtained by processing the data of the TS for the creation of a classification model. Results showed a recognition of 127 samples out of 138, equal to $92.0 \%$ of correct classification rate.

Table 3. Confusion matrix elaborated with the TS dataset.

\begin{tabular}{ccccccc}
\hline TS & Classes & \multicolumn{5}{c}{ Predicted } \\
\hline \multirow{4}{*}{ Actual } & RP & OF & CA & AA & TOT \\
& RP & 19 & 0 & 3 & 0 & 22 \\
& OF & 2 & 34 & 0 & 0 & 36 \\
& CA & 2 & 0 & 35 & 1 & 38 \\
& AA & 3 & 0 & 0 & 39 & 42 \\
\hline
\end{tabular}

According to the study of Mahmodi et al. [45] the obtained prediction model was applied to the TS + VS dataset to verify the influence on unknown samples on the model accuracy (Table 4). Results show that the samples misclassified resulted in the same both for the TS and TS + VS dataset, while the correct classification rate resulted in being equal to $92.5 \%$.

Table 4. Confusion matrix elaborated with the TS + VS dataset.

\begin{tabular}{ccccccc}
\hline TS + VS & Classes & \multicolumn{5}{c}{ Predicted } \\
\hline \multirow{4}{*}{ Actual } & RP & OF & CA & AA & TOT \\
& RP & 21 & 0 & 3 & 0 & 24 \\
& OF & 2 & 36 & 0 & 0 & 38 \\
& CA & 2 & 0 & 37 & 1 & 40 \\
& AA & 3 & 0 & 0 & 41 & 44 \\
\hline
\end{tabular}

3.2. Influence of the Internal Temperature on the Measured Values of the Sensors in Terms of Resistance

Figure 3 reports the values of the $\mathrm{R}^{2}$ correlation coefficients between the chamber temperature and the sensors values in terms of electrical resistance, detected inside the measurement chamber, for each odor class, by considering the TS + VS dataset. 


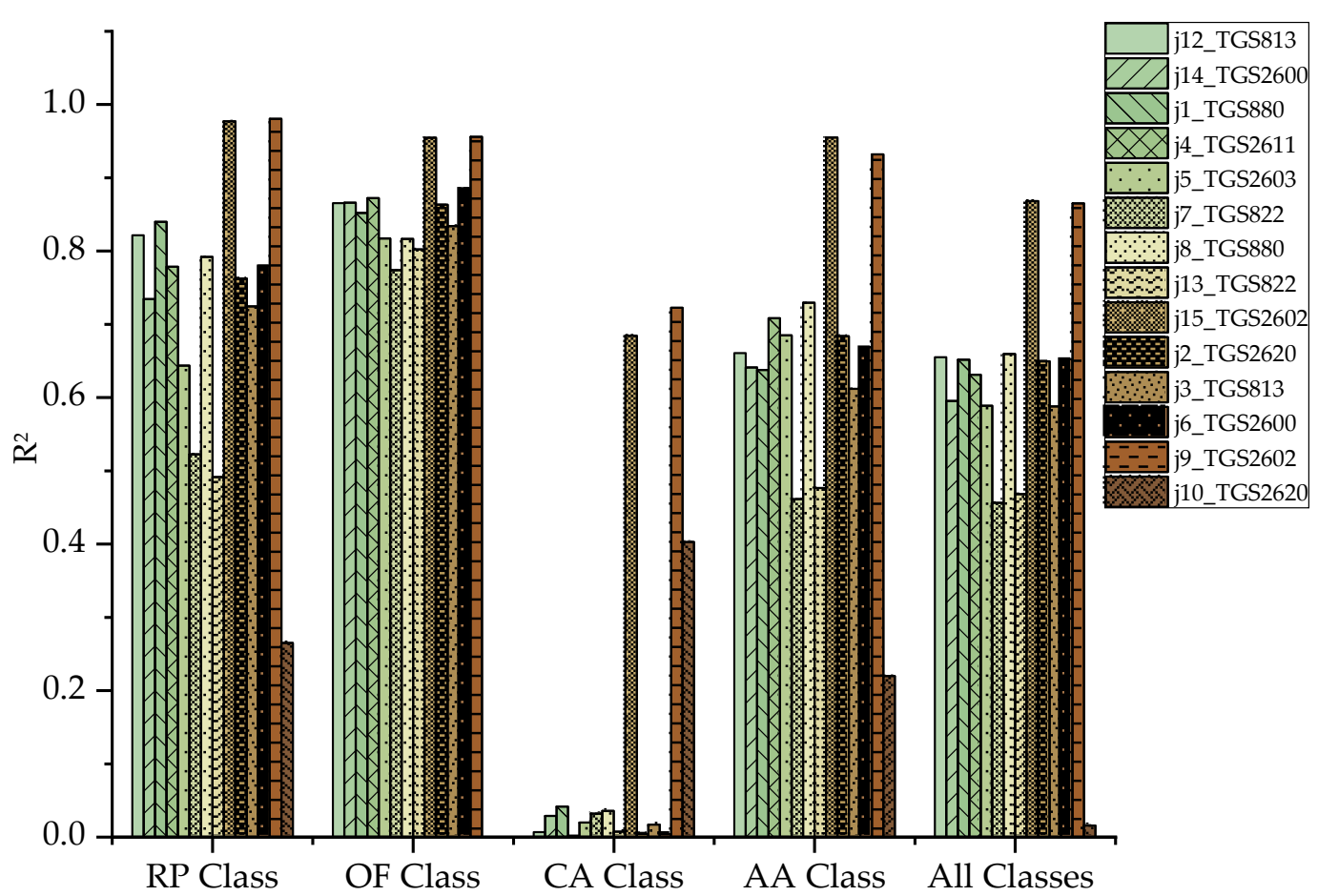

Figure 3. $\mathrm{R}^{2}$ correlation coefficients values for each sensor and odour class in the training mode.

Table 5 shows the averages and standard deviation values of the acquisition temperatures of the samples of the TS + VS acquired.

Table 5. Average and standard deviation values of the acquisition temperatures for each odour class.

\begin{tabular}{cc}
\hline Class & Average Temperature $\left[{ }^{\circ} \mathbf{C}\right]$ \\
\hline RP & $48 \pm 4$ \\
OF & $47 \pm 5$ \\
CA & $46 \pm 2$ \\
AA & $47 \pm 3$ \\
\hline
\end{tabular}

Comparing the resistance values of the single acquisitions, for each class and for each sensor, with the corresponding acquisition temperature a relationship of inverse proportionality between the temperature $(\mathrm{T})$ and the resistances $(\mathrm{R})$ has been confirmed [46].

For all the investigated classes, the two TGS2602 sensors (Figaro, Arlington Heights, $\mathrm{IL}$, USA) showed $\mathrm{R}^{2}$ coefficients higher than 0.86 , except for samples of "CA" class. For "CA" class, in fact, the resistance values resulted in less being affected by the temperature fluctuation, since the lowest variation of the acquisition temperature was among the samples.

Even if the correlation curves have been calculated also for the different odour classes separately, to avoid the influence of the specific conditions on the model results the corrective factors were calculated considering all the samples together. For all the classes, the sensor that demonstrated the lowest R2 value resulted the sensor j10_TGS2620. The TGS2620 sensor is present at both levels (j2_TGS2620_Level I, j10_TGS2620—Level II), with a different conditioning of the resistances. Consequently, the dependence of the sensor on the operating temperature resulted almost negligible for the sensors at the channel j10 (II level) since the lower sensitivity of the sensor to the electrical signals. Conversely, the sensors TGS2602 showed high R2 for all the investigated class. 


\subsection{Optimization of the Classification Models and Performance Parameters}

In Table 6, the confusion matrix obtained by applying the prediction model to the TS + VS samples after the application of the correction coefficients was reported.

Table 6. TS + VS confusion matrix with the application of correction coefficients.

\begin{tabular}{ccccccc}
\hline TS + VS & Classes & \multicolumn{5}{c}{ Predicted } \\
\hline \multirow{4}{*}{ Actual } & RP & OF & CA & AA & TOT \\
& RP & 23 & 0 & 1 & 0 & 24 \\
& OF & 2 & 36 & 0 & 0 & 38 \\
& CA & 0 & 0 & 40 & 0 & 40 \\
& AA & 2 & 0 & 0 & 42 & 44 \\
\hline
\end{tabular}

The results in terms of accuracy performances have been reported in Figure 4, in which the performance indicators have been calculated per class for the TS + VS dataset before and after the application of the corrective factors.

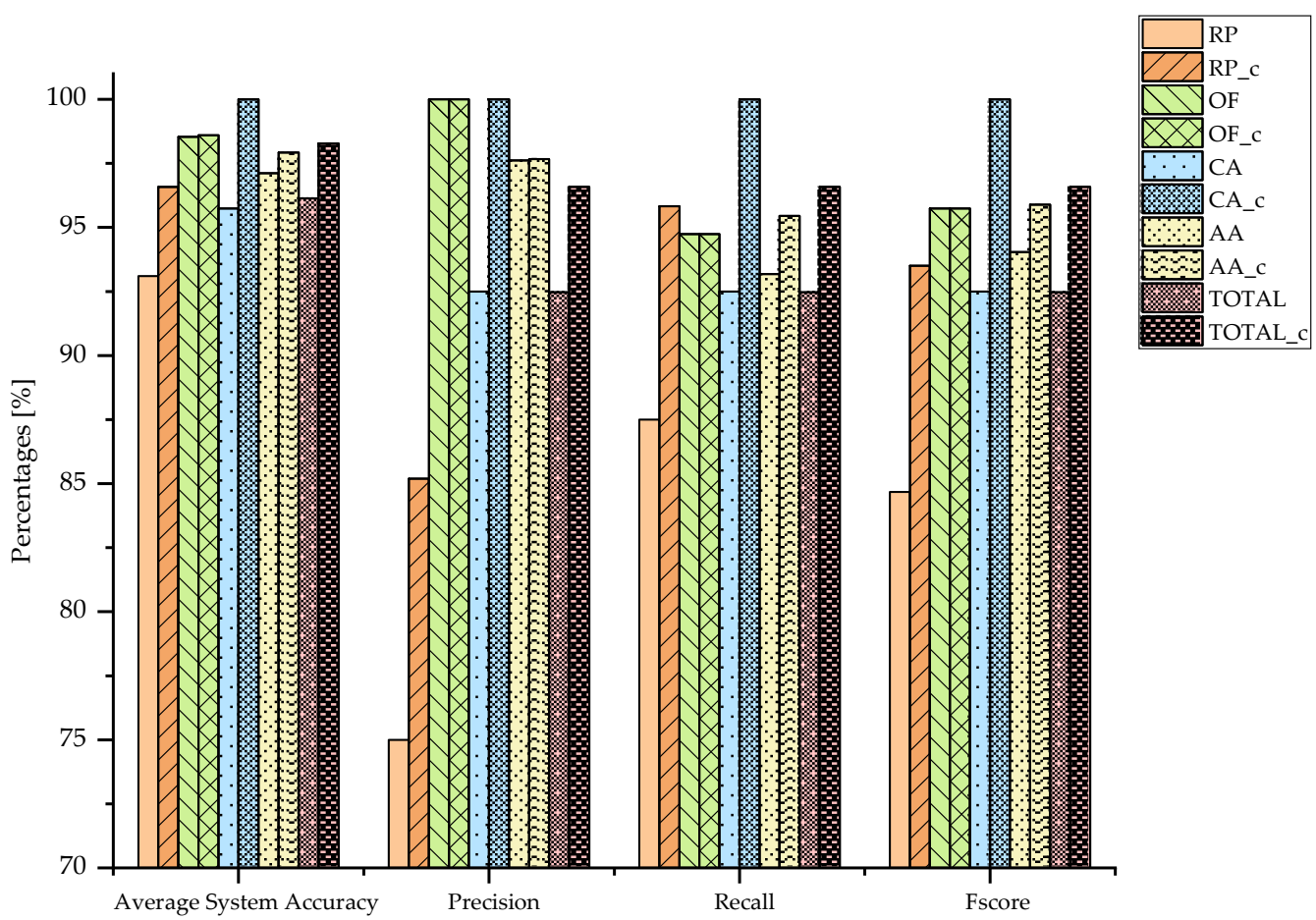

Figure 4. Comparison between model performances on TS + VS dataset, per each class, before (RP, OF, CA, AA, TOTAL) and after (RP_c, OF_c, CA_c, AA_c, TOTAL_c) the application of correction coefficients.

Applying the corrective coefficients to the raw data of the 146 samples (TS + VS Set), a significant improvement in terms of recognition performance was obtained. In fact, according to the results of the confusion matrix reported in Table 5, the misclassified samples decreased from 11 to 5 . The results have been confirmed in the graph in Figure 4, in which a remarkable improvement in terms of classification performances mainly for RP and CA odour classes can clearly be observed.

The strong dependence of almost all sensors on the operating parameters has been indeed reduced by considering the actual acquisition temperatures. The highest accuracy was detected for the OF class, for which, by applying the corrective coefficients, an accuracy of $98.6 \%$ was obtained. The overall accuracy increased from $96.1 \%$ to $98.3 \%$. All the classes, after the application of the afore-mentioned coefficients, showed accuracies over $96 \%$. 


\section{Conclusions}

The possibility to continuously monitor all the parameters that can affect the operating modes of the IOMS system and their results is a fundamental element to increase the model prediction results and performances. In the present study, the temperature of the gaseous flux in the measurement chamber was highlighted as an important variable to be monitored continuously, given their influence on the values detected by the IOMS sensors. The work also provided a useful methodology experimentally validated to reduce the influence of operating conditions, in terms of temperature and consequently humidity, on the model performances. Corrective factors have been retrieved by analysing the dependence of resistance values on temperature, by optimizing an algorithm automatically applied. The automatic application of corrective coefficients, calculated with dedicated software thus proved to be a useful tool for increasing the reliability of the predictive model, since in the conditions investigated the accuracy of the model increased from $96 \%$ to $98 \%$.

The study promotes the development of flexible and robust IOMS devices, with highly adaptable architecture and dedicated software, capable of continuous analysis of all operating parameters and taking them into account in measures to overcome the current limitations in monitoring environmental odours.

Author Contributions: Conceptualization, G.O., V.N. and T.Z.; methodology, G.O. and T.Z.; software, A.B., V.S. and G.O.; validation, V.B., V.N., T.Z. and A.B.; formal analysis, G.O.; investigation, G.O. and R.M.; resources, V.B., V.N. and T.Z.; data curation, G.O., A.B. and R.M.; writing-original draft preparation and review and editing G.O., T.Z., V.S., A.B. and R.M.; supervision, V.N., T.Z. and V.B.; project administration, T.Z. and V.N.; funding acquisition T.Z. All authors have read and agreed to the published version of the manuscript.

Funding: This research was funded by University of Salerno, FARB projects: 300393FRB19ZARRA and 300393FRB20ZARRA.

Institutional Review Board Statement: Not applicable.

Informed Consent Statement: Not applicable.

Data Availability Statement: The data presented in this study are available on request from the corresponding author.

Acknowledgments: The authors would like to express their sincere gratitude to Paolo Napodano for technical assistance. The Inter-University Consortium for Prediction and Prevention of Relevant Hazards (Consorzio inter-Universitario per la previsione e la prevenzione dei Grandi Rischi, C.U.G.RI.), Sartec and Sponge are acknowledged for technical support.

Conflicts of Interest: The authors declare no conflict of interest.

\section{References}

1. Oliva, G.; Zarra, T.; Pittoni, G.; Senatore, V.; Galang, M.G.; Castellani, M.; Belgiorno, V.; Naddeo, V. Next-Generation of Instrumental Odour Monitoring System (IOMS) for the Gaseous Emissions Control in Complex Industrial Plants. Chemosphere 2021, 271, 129768. [CrossRef] [PubMed]

2. Giuliani, S.; Zarra, T.; Nicolas, J.; Naddeo, V.; Belgiorno, V.; Romain, A.C. An Alternative Approach of the E-Nose Training Phase in Odour Impact Assessment. Chem. Eng. Trans. 2012, 30, 139-144.

3. Zarra, T.; Giuliani, S.; Naddeo, V.; Belgiorno, V. Control of Odour Emission in Wastewater Treatment Plants by Direct and Undirected Measurement of Odour Emission Capacity. Water Sci. Technol. 2012, 66, 1627-1633. [CrossRef]

4. Gostelow, P.; Parsons, S.A.; Stuetz, R.M. Odour Measurements for Sewage Treatment Works. Water Res. 2001, $35,579-597$. [CrossRef]

5. Oliva, G.; Ángeles, R.; Rodríguez, E.; Turiel, S.; Naddeo, V.; Zarra, T.; Belgiorno, V.; Muñoz, R.; Lebrero, R. Comparative evaluation of a biotrickling filter and a tubular photobioreactor for the continuous abatement of toluene. J. Hazard. Mater. 2019, 380, 120860. [CrossRef]

6. Naddeo, V.; Zarra, T.; Oliva, G.; Kubo, A.; Uchida, N.; Higuchi, T. Odour Measurement in Wastewater Treatment Plant by a New Prototype of e.Nose: Correlation and Comparison Study with Reference to Both European and Japanese Approaches. Chem. Eng. Trans. 2016, 54, 85-90. [CrossRef]

7. Naddeo, V.; Belgiorno, V.; Zarra, T. (Eds.) Odour Impact Assessment Handbook; John Wiley \& Sons: Chichester, UK; Hoboken, NJ, USA, 2013; ISBN 978-1-118-48128-8. 
8. Naddeo, V.; Zarra, T.; Oliva, G.; Chiavola, A.; Vivarelli, A. Environmental Odour Impact Assessment of Landfill Expansion Scenarios: Case Study of Borgo Montello (Italy). Chem. Eng. Trans. 2016, 54, 73-78. [CrossRef]

9. Bokowa, A.; Diaz, C.; Koziel, J.A.; McGinley, M.; Barclay, J.; Schauberger, G.; Guillot, J.-M.; Sneath, R.; Capelli, L.; Zorich, V.; et al. Summary and Overview of the Odour Regulations Worldwide. Atmosphere 2021, 12, 206. [CrossRef]

10. Senatore, V.; Zarra, T.; Oliva, G.; Belgiorno, V.; Naddeo, V. Volatile Organic Compounds (Vocs) Removal by Combining Bioscrubber and Ozone Pretreatment. Glob. Nest J. 2020, 22, 143-146. [CrossRef]

11. Blanco-Rodríguez, A.; Camara, V.F.; Campo, F.; Becherán, L.; Durán, A.; Vieira, V.D.; de Melo, H.; Garcia-Ramirez, A.R. Development of an Electronic Nose to Characterize Odours Emitted from Different Stages in a Wastewater Treatment Plant. Water Res. 2018, 134, 92-100. [CrossRef]

12. Cadena, E.; Adani, F.; Font, X.; Artola, A. Including an Odor Impact Potential in Life Cycle Assessment of waste treatment plants. Int. J. Environ. Sci. Technol. 2018, 15, 2193-2202. [CrossRef]

13. Zarra, T.; Galang, M.G.; Ballesteros, F.; Belgiorno, V.; Naddeo, V. Environmental Odour Management by Artificial Neural Network-A Review. Environ. Int. 2019, 133, 105189. [CrossRef]

14. Okur, S.; Sarheed, M.; Huber, R.; Zhang, Z.; Heinke, L.; Kanbar, A.; Wöll, C.; Nick, P.; Lemmer, U. Identification of Mint Scents Using a QCM Based E-Nose. Chemosensors 2021, 9, 31. [CrossRef]

15. Wilson, A.D. Applications of Electronic-Nose Technologies for Noninvasive Early Detection of Plant, Animal and Human Diseases. Chemosensors 2018, 6, 45. [CrossRef]

16. Huang, J.; Wu, J. Robust and Rapid Detection of Mixed Volatile Organic Compounds in Flow Through Air by a Low Cost Electronic Nose. Chemosensors 2020, 8, 73. [CrossRef]

17. Gardner, J.W.; Bartlett, P.N. A Brief History of Electronic Noses. Sens. Actuators B Chem. 1994, 18, 210-211. [CrossRef]

18. Mota, I.; Teixeira-Santos, R.; Rufo, J.C. Detection and Identification of Fungal Species by Electronic Nose Technology: A Systematic Review. Fungal Biol. Rev. 2021, S1749461321000142. [CrossRef]

19. Röck, F.; Barsan, N.; Weimar, U. Electronic Nose: Current Status and Future Trends. Chem. Rev. 2008, 108, 705-725. [CrossRef]

20. Baietto, M.; Wilson, A. Electronic-Nose Applications for Fruit Identification, Ripeness and Quality Grading. Sensors 2015, 15, 899-931. [CrossRef] [PubMed]

21. Kiani, S.; Minaei, S.; Ghasemi-Varnamkhasti, M. Application of Electronic Nose Systems for Assessing Quality of Medicinal and Aromatic Plant Products: A Review. J. Appl. Res. Med. Aromat. Plants 2016, 3, 1-9. [CrossRef]

22. Montuschi, P.; Mores, N.; Trové, A.; Mondino, C.; Barnes, P.J. The Electronic Nose in Respiratory Medicine. Respiration 2013, 85, 72-84. [CrossRef]

23. Jia, P.; Tian, F.; He, Q.; Fan, S.; Liu, J.; Yang, S.X. Feature Extraction of Wound Infection Data for Electronic Nose Based on a Novel Weighted KPCA. Sens. Actuators B Chem. 2014, 201, 555-566. [CrossRef]

24. Deshmukh, S.; Bandyopadhyay, R.; Bhattacharyya, N.; Pandey, R.A.; Jana, A. Application of Electronic Nose for Industrial Odors and Gaseous Emissions Measurement and Monitoring-An Overview. Talanta 2015, 144, 329-340. [CrossRef] [PubMed]

25. Licen, S.; Barbieri, G.; Fabbris, A.; Briguglio, S.C.; Pillon, A.; Stel, F.; Barbieri, P. Odor Control Map: Self Organizing Map Built from Electronic Nose Signals and Integrated by Different Instrumental and Sensorial Data to Obtain an Assessment Tool for Real Environmental Scenarios. Sens. Actuators B Chem. 2018, 263, 476-485. [CrossRef]

26. Gobbi, E.; Falasconi, M.; Zambotti, G.; Sberveglieri, V.; Pulvirenti, A.; Sberveglieri, G. Rapid Diagnosis of Enterobacteriaceae in Vegetable Soups by a Metal Oxide Sensor Based Electronic Nose. Sens. Actuators B Chem. 2015, 207, 1104-1113. [CrossRef]

27. Loutfi, A.; Coradeschi, S.; Mani, G.K.; Shankar, P.; Rayappan, J.B.B. Electronic Noses for Food Quality: A Review. J. Food Eng. 2015, 144, 103-111. [CrossRef]

28. Korsa, M.T.; Domingo, J.M.C.; Nsubuga, L.; Hvam, J.; Niekiel, F.; Lofink, F.; Rubahn, H.-G.; Adam, J.; Hansen, R.D.O. Optimizing Piezoelectric Cantilever Design for Electronic Nose Applications. Chemosensors 2020, 8, 114. [CrossRef]

29. Suchorab, Z.; Frąc, M.; Guz, Ł.; Oszust, K.; Łagód, G.; Gryta, A.; Bilińska-Wielgus, N.; Czerwiński, J. A Method for Early Detection and Identification of Fungal Contamination of Building Materials Using E-Nose. PLoS ONE 2019, 14, e0215179. [CrossRef]

30. Giungato, P.; Di Gilio, A.; Palmisani, J.; Marzocca, A.; Mazzone, A.; Brattoli, M.; Giua, R.; de Gennaro, G. Synergistic Approaches for Odor Active Compounds Monitoring and Identification: State of the Art, Integration, Limits and Potentialities of Analytical and Sensorial Techniques. TrAC Trends Anal. Chem. 2018, 107, 116-129. [CrossRef]

31. Moufid, M.; Bouchikhi, B.; Tiebe, C.; Bartholmai, M.; El Bari, N. Assessment of Outdoor Odor Emissions from Polluted Sites Using Simultaneous Thermal Desorption-Gas Chromatography-Mass Spectrometry (TD-GC-MS), Electronic Nose in Conjunction with Advanced Multivariate Statistical Approaches. Atmos. Environ. 2021, 256, 118449. [CrossRef]

32. De Vito, S.; Massera, E.; Piga, M.; Martinotto, L.; Di Francia, G. On Field Calibration of an Electronic Nose for Benzene Estimation in an Urban Pollution Monitoring Scenario. Sens. Actuators B Chem. 2008, 129, 750-757. [CrossRef]

33. Ghasemi-Varnamkhasti, M.; Mohtasebi, S.S.; Rodriguez-Mendez, M.L.; Lozano, J.; Razavi, S.H.; Ahmadi, H. Potential Application of Electronic Nose Technology in Brewery. Trends Food Sci. Technol. 2011, 22, 165-174. [CrossRef]

34. Burlachenko, J.; Kruglenko, I.; Snopok, B.; Persaud, K. Sample Handling for Electronic Nose Technology: State of the Art and Future Trends. TrAC Trends Anal. Chem. 2016, 82, 222-236. [CrossRef]

35. Makarichian, A.; Amiri Chayjan, R.; Ahmadi, E.; Mohtasebi, S.S. Assessment the Influence of Different Drying Methods and Pre-Storage Periods on Garlic (Allium Sativum L.) Aroma Using Electronic Nose. Food Bioprod. Process. 2021, 127, 198-211. [CrossRef] 
36. Laga, S.A.; Sarno, R. Temperature Effect of Electronic Nose Sampling for Classifying Mixture of Beef and Pork. Indones. J. Electr. Eng. Comput. Sci. 2020, 19, 1626-1634. [CrossRef]

37. Liang, Z.; Tian, F.; Yang, S.X.; Zhang, C.; Sun, H.; Liu, T. Study on Interference Suppression Algorithms for Electronic Noses: A Review. Sensors 2018, 18, 1179. [CrossRef] [PubMed]

38. Tian, H.; Yu, B.; Yu, H.; Chen, C. Evaluation of the Synergistic Olfactory Effects of Diacetyl, Acetaldehyde, and Acetoin in a Yogurt Matrix Using Odor Threshold, Aroma Intensity, and Electronic Nose Analyses. J. Dairy Sci. 2020, 103, 7957-7967. [CrossRef] [PubMed]

39. Majchrzak, T.; Wojnowski, W.; Dymerski, T.; Gębicki, J.; Namieśnik, J. Electronic Noses in Classification and Quality Control of Edible Oils: A Review. Food Chem. 2018, 246, 192-201. [CrossRef] [PubMed]

40. Yu, H.; Wang, J.; Zhang, H.; Yu, Y.; Yao, C. Identification of Green Tea Grade Using Different Feature of Response Signal from E-Nose Sensors. Sens. Actuators B Chem. 2008, 128, 455-461. [CrossRef]

41. Sanaeifar, A.; Mohtasebi, S.S.; Ghasemi-Varnamkhasti, M.; Ahmadi, H. Application of MOS Based Electronic Nose for the Prediction of Banana Quality Properties. Measurement 2016, 82, 105-114. [CrossRef]

42. Tharwat, A.; Gaber, T.; Ibrahim, A.; Hassanien, A.E. Linear Discriminant Analysis: A Detailed Tutorial. AI Commun. 2017, 30, 169-190. [CrossRef]

43. Rousson, V.; Goşoniu, N.F. An R-Square Coefficient Based on Final Prediction Error. Stat. Methodol. 2007, 4, 331-340. [CrossRef]

44. Sokolova, M.; Lapalme, G. A Systematic Analysis of Performance Measures for Classification Tasks. Inf. Process. Manag. 2009, 45, 427-437. [CrossRef]

45. Mahmodi, K.; Mostafaei, M.; Mirzaee-Ghaleh, E. Detection and Classification of Diesel-Biodiesel Blends by LDA, QDA and SVM Approaches Using an Electronic Nose. Fuel 2019, 258, 116114. [CrossRef]

46. Huerta, R.; Mosqueiro, T.S.; Fonollosa, J.; Rulkov, N.F.; Rodriguez-Lujan, I. Online Decorrelation of Humidity and Temperature in Chemical Sensors for Continuous Monitoring. Chemom. Intell. Lab. Syst. 2016, 157, 169-176. [CrossRef] 